\title{
Antioxidant and Antibacterial Activity of the Beverage Obtained by Fermentation of Sweetened Lemon Balm (Melissa officinalis L.) Tea with Symbiotic Consortium of Bacteria and Yeasts
}

\author{
Aleksandra S. Velićanski*, Dragoljub D. Cvetković, Siniša L. Markov, \\ Vesna T. Tumbas Šaponjac and Jelena J. Vulić
}

Faculty of Technology, University of Novi Sad, Bulevar cara Lazara 1, RS-21000 Novi Sad, Serbia

Received: February 6, 2014

Accepted: August 28, 2014

\begin{abstract}
Summary
Kombucha is a fermented tea beverage which is traditionally prepared by fermenting sweetened black or green tea (Camellia sinensis L.) with symbiotic consortium of bacteria and yeasts (SCOBY). In this study, lemon balm (Melissa officinalis L.) was used as the only nitrogen source for kombucha fermentation. During the seven-day fermentation process, $\mathrm{pH}$ value, titratable acidity (TA), total phenolic content, phenolic compounds, and antioxidant activity against hydroxyl ( $\left.{ }^{\circ} \mathrm{OH}\right)$ and 1,1-diphenyl-2-picrylhydrazil (DPPH) radicals were measured to detect the connection between the fermentation time and antioxidant and antibacterial activities of lemon balm kombucha. Antibacterial activity of finished beverages with optimum acidity $(\mathrm{TA}=4-4.5 \mathrm{~g} / \mathrm{L})$, the value which is confirmed by long-time kombucha consumers, and enhanced acidity $(\mathrm{TA}=8.12 \mathrm{~g} / \mathrm{L})$ was tested against eleven wild bacterial strains. The results showed that lemon balm could be successfully used as an alternative to $C$. sinensis L. for kombucha fermentation. Total phenolic content and antioxidant activity against DPPH radicals of lemon balm fermentation broth were higher than those of traditional kombucha. Rosmarinic acid is the main phenolic compound of the lemon balm-based kombucha that probably provides biological activity of the beverage. Judging from the $\mathrm{EC}_{50}$ values, kombucha beverages exhibited higher antioxidant activities compared with $C$. sinensis L. and M. officinalis L. infusions, which can probably be ascribed to SCOBY metabolites. Lemon balm kombucha with both optimum and enhanced acidity showed antibacterial activity, which can be primarily ascribed to acetic acid, but also to some other tea components and SCOBY metabolites.
\end{abstract}

Key words: kombucha, lemon balm tea, antioxidant activity, antibacterial activity

\section{Introduction}

Kombucha is a traditional fermented beverage which originated in northeast China (Manchuria) in 220 BC and then was spread to Russia, Germany and the rest of the world (1). Kombucha is sometimes reffered to as tea fungus, mother, or mushroom, although the actual fermenting organisms are a symbiotic consortium of bacteria and yeasts, known as SCOBY (2). This consortium includes acetic acid bacteria (Acetobacter aceti, Acetobacter pasteurianus and Gluconobacter oxydans) and yeasts (Saccharomyces spp., Torulopsis spp., Pichia spp., Brettanomyces spp., Zygosaccharomyces kombuchaensis, etc.) (3-5). Sucrose as a carbon source in the cultivation medium is hydrolyzed by the enzyme invertase from yeasts in the SCOBY. The yeasts ferment glucose and fructose to ethanol, which is then oxidized by acetic acid bacteria to acetic acid. This is 
the main metabolic path of kombucha fermentation, and acetic acid, ethanol and gluconic acid are the main SCOBY products $(1,6)$. Other components present in kombucha beverage are sugars, ethyl gluconate, oxalic, saccharic, lactic, keto-gluconic and amino acids, water-soluble vitamins, tea components (catehins, theaflavins, flavonols, etc.) and hydrolytic enzymes (invertase, amylase, etc.) (7-9).

Strong and increasing interest in the consumption of the product derives from its purported therapeutic benefits, which range from mass loss to curing cancer and AIDS $(3,10)$. These effects have not been validated scientifically, but they could be attributed to the presence of gluconic, glucuronic and amino acids, vitamins, and micronutrients produced during fermentation (11).

Sweetened black or green tea (Camellia sinensis L.) is the traditional and almost only recommended medium for preparing kombucha because of high levels of nitrogen sources (like purine derivatives, caffeine and theophylline) which are necessary for growth and reproduction of SCOBY cells $(12,13)$. Although it has been noticed that some herbal teas cannot be used as alternative nitrogen sources due to the lack of purine derivatives (12), sweetened echinacea (Echinacea purpurea L.) and winter savory (Satureja montana L.) have been demonstrated as suitable tea alternatives, yielding a fermentation product in a shorter time and comparable to the traditional beverage with regard to the basic chemical and microbiological characteristics (14). Also, lemon balm (Melissa officinalis L.) can be successfully used as nitrogen source for kombucha fermentation (15). This aromatic herb is cultivated throughout the world because of its application in several fields. In medicine it is used for the treatment of headaches, gastrointestinal disorders, nervousness, anemia, bronchitis, high blood pressure, rheumatism, and enhancing memory. In food industry, it is used to add flavour to different food and beverage products, and it is also popular in the perfume and cosmetic industry (16-19). Antioxidant and antimicrobial potentials of fresh and dry Melissa officinalis L. leaves, extracts and essential oil have been demonstrated in previous studies (20-22). Therefore, the use of lemon balm for kombucha fermentation can yield a beverage with improved functional characteristics compared to the traditional kombucha prepared from black tea. The first results show that the lemon balm kombucha has significant antioxidant and antimicrobial activities $(23,24)$. Hence, the aim of this study is to investigate the connection between the fermentation time and antioxidant (against hydroxyl and DPPH radicals) and antibacterial (against wild bacterial strains) activities of lemon balm kombucha. Changes in the $\mathrm{pH}$, titratable acidity, total phenols, and phenolic compounds as possible active components of the beverage during a 7-day fermentation of the sweetened lemon balm tea were determined.

\section{Materials and Methods}

\section{Plant material}

Aerial parts of the cultivated flowering plant Melissa officinalis L. were collected in July 2009 in the Province of Vojvodina, Republic of Serbia. Voucher specimens (num- ber 2184) were confirmed and deposited at the Herbarium of the Department of Biology and Ecology, Faculty of Sciences, University of Novi Sad, Novi Sad, Serbia.

\section{SCOBY}

Fermentation was performed using the local household culture, for which previous investigations showed that it contained at least five yeast strains (Saccharomycodes ludwigii, Saccharomyces cerevisiae, Saccharomyces bisporus, Torulopsis sp. and Zygosaccharomyces sp.) and two bacterial strains of the Acetobacter genus (25).

\section{Fermentation conditions}

All experiments were performed on sweetened infusions made by dissolving $70 \mathrm{~g}$ of sucrose in $1 \mathrm{~L}$ of tap water. To the boiled water, $5 \mathrm{~g} / \mathrm{L}$ of lemon balm or black tea (Fructus, Bačka Palanka, Serbia) were added and removed by filtration after $15 \mathrm{~min}$. After cooling to room temperature, the sweetened infusions were inoculated with 100 $\mathrm{mL} / \mathrm{L}$ of fermentation broth containing the SCOBY. Small bioreactors (volume $0.72 \mathrm{~L}$, diameter $80 \mathrm{~mm}$ ) were filled in with $0.33 \mathrm{~L}$ of inoculated liquid phase. The bioreactors were covered with cheesecloth, and the fermentation at $(28 \pm 1){ }^{\circ} \mathrm{C}$ was monitored for seven days. Fermentation broth and kombucha beverage obtained from traditional medium (sweetened black tea) under the same fermentation conditions served as the control.

\section{Sampling}

Sampling of lemon balm and black tea fermentation broths was performed under aseptic conditions at the beginning of fermentation (sweetened tea and inoculated medium), and then after 1, 2, 3, 4, 5 and 7 days of the process. Samples for the determination of total phenols, HPLC analyses, antioxidant and antimicrobial tests were filtered through a sterile microfilter $(0.22 \mu \mathrm{m})$ to remove the cells.

\section{Determination of $\mathrm{pH}$ and titratable acidity}

The $\mathrm{pH}$ values were measured using an electronic $\mathrm{pH}$ meter (HI 9321, HANNA Instruments) calibrated at $\mathrm{pH}=4.0$ and 7.0. After removing $\mathrm{CO}_{2}$ from the fermentation broth, a $20-\mathrm{mL}$ aliquot was taken and titrated with 0.1 $\mathrm{mol} / \mathrm{L}$ of $\mathrm{NaOH}$. The titratable acidity (TA) was expressed in grams of acetic acid per litre of the sample (26).

\section{Determination of total phenolic concentration}

Total phenolic concentration was determined spectrophotometrically according to Folin-Ciocalteu colorimetric method (27) and expressed as $\mu \mathrm{g}$ per $\mathrm{mL}$ of gallic acid equivalents (GAE).

\section{High-performance liquid chromatography of the polyphenolic compounds}

Samples were injected into a Waters high-performance liquid chromatography (HPLC) system consisting of 1525 binary pumps, a thermostat and 717+ autosampler connected to a Waters 2996 diode array detector (Waters, 
Milford, CT, USA). The separation of phenolics was performed on a Symmetry C-18 RP column $(125 \mathrm{~mm} \times 4 \mathrm{~mm})$ with 5- $\mu \mathrm{m}$ particle size (Waters) and an appropriate guard column. Two mobile phases, A phosphoric acid $0.1 \%$ and B acetonitrile (J. T. Baker, Deventer, the Netherlands), were used at a flow rate of $1 \mathrm{~mL} / \mathrm{min}$ with the following gradient profile: $20 \mathrm{~min}$ from $10-22 \% \mathrm{~B}, 20 \mathrm{~min}$ with a linear rise to $40 \% \mathrm{~B}, 5 \mathrm{~min}$ reverse to $10 \% \mathrm{~B}$, and additional $5 \mathrm{~min}$ of equilibration time. Peaks of the detected compounds were located and identified on the HPLC-UV chromatograms through comparison of separated standards with authentic samples by combining their retention times and UV spectra obtained by diode array detector (DAD). Volumes of injected samples were adjusted to fit within the linear calibration range determined by injection of selected commercial standards. The calibration curves were made by injection of different volumes from the stock solutions over the range of concentrations observed for each of the compounds, using linear regression for the relationship of the sum of peak areas vs. concentration, under the same conditions as for the sample analysis. Each component was analyzed quantitatively by the external standard method using pure compounds (gallic, protocatechuic, chlorogenic, caffeic, syringic, ferulic, sinapic, gentisic, isoferulic, rosmarinic and $p$-coumaric acids, vanillin, epicatechin, epicatechin gallate, catechin, resveratrol, kaempferol, myricetin, apigenin, luteolin, quercetin and rutin) as references for concentration, retention time and characteristic UV spectra. DAD response was linear in the whole concentration range for all standard compounds. Data acquisition and spectral evaluation for peak confirmation were carried out successfully using Empower v. 2 software (Waters, Milford, MA, USA).

\section{Determination of antioxidant activity of lemon balm kombucha}

DPPH scavenging activity was evaluated according to Čanadanović-Brunet et al. (28). Blank probe was obtained by mixing $0.2 \mathrm{~mL}$ of water and $0.4 \mathrm{~mL}$ of $0.4 \mathrm{mM}$ methanol solution of DPPH'. The effect of fermentation broth or tea on $\mathrm{DPPH}^{-}$was studied in the volume ratio of $50-333.3 \mathrm{~mL} / \mathrm{L}$ while keeping the volume ratio of water constant $(330 \mathrm{~mL} / \mathrm{L})$. After that, the mixture was stirred for 2 min and transferred to an ER-16FT flat cell (Bruker, Rheinstetten, Germany). The electron spin resonance (ESR) spectra were recorded on an ESR spectrometer (model 300E, Bruker) under the following conditions: field modulation $100 \mathrm{kHz}$, modulation amplitude $0.256 \mathrm{G}$, time constant $40.96 \mathrm{~ms}$, conversion time $335.544 \mathrm{~ms}$, centre field $3440.00 \mathrm{G}$, sweep width $100.00 \mathrm{G}$, x-band frequency 9.45 $\mathrm{GHz}$, power $7.96 \mathrm{~mW}$ and temperature $23^{\circ} \mathrm{C}$. The scavenging activity of fermentation broth and tea against $\mathrm{DPPH}^{\circ}$ radical was defined as:

$$
\text { DPPH' scavenging activity }=\left(h_{0}-h_{\mathrm{x}}\right) / h_{0} \cdot 100
$$

where $h_{0}$ and $h_{\mathrm{x}}$ are the heights of the second peak in the ESR spectrum of DPPH radicals of the blank and the probe, respectively.

Hydroxyl radical scavenging activity was evaluated as reported by Čanadanović-Brunet et al. (28). Hydroxyl radicals were obtained by the Fenton reaction and detected by spin trapping in a system consisting of (in $\mathrm{mL}$ ): $\mathrm{H}_{2} \mathrm{O}_{2}$ $0.2(2 \mathrm{mM}), \mathrm{FeCl}_{2} 0.2(0.3 \mathrm{mM})$, water 0.2 and 5,5-dimethyl-1-pyrroline $\mathrm{N}$-oxide (DMPO) $0.2(112 \mathrm{mM})$ as spin trap (control sample). The influence of fermentation broth and tea on the amount of hydroxyl radicals trapped by DMPO was studied by adding them to the reaction system in the volume ratio of $10-333.3 \mathrm{~mL} / \mathrm{L}$. The ESR spectra were recorded 2.5 min after mixing on the above ESR spectrometer, with the following settings: modulation amplitude $0.512 \mathrm{G}$, receiver gain $10^{4}$, time constant $81.92 \mathrm{~ms}$, conversion time $163.84 \mathrm{~ms}$, centre field $3440.00 \mathrm{G}$, sweep width $100.00 \mathrm{G}$, x-band frequency $9.64 \mathrm{GHz}$, power $20 \mathrm{~mW}$ and temperature $23^{\circ} \mathrm{C}$. The hydroxyl radical scavenging activity of the fermentation broth and tea was defined as:

$$
\cdot \mathrm{OH} \text { scavenging activity }=\left(h_{0}-h_{\mathrm{x}}\right) / h_{0} \cdot 100
$$

where $h_{0}$ and $h_{\mathrm{x}}$ are the hights of the second peak in the ESR spectrum of DMPO/'OH spin adduct of the samples without and with fermentation broth or tea, respectively.

Antioxidant activities of lemon balm and traditional fermentation broths against both, DPPH and $\mathrm{OH}$, radicals are expressed as $\mathrm{EC}_{50}$ values. The $\mathrm{EC}_{50}$ value is defined as the concentration of the extract (in this study it represents the volume $(\mu \mathrm{L})$ of kombucha beverages or tea infusions per $\mathrm{mL}$ of reaction mixture) required for $50 \%$ scavenging of DPPH or hydroxyl radicals under experimental conditions employed (29).

\section{Determination of antibacterial activity of lemon balm kombucha}

Samples for the determination of the antibacterial activity were: lemon balm kombucha beverages with different acidity (TA=4.44 and $8.12 \mathrm{~g} / \mathrm{L})$, acetic acid solutions of the same concentration as fermented lemon balm tea $(4.44$ and $8.12 \mathrm{~g} / \mathrm{L})$, decoction of unfermented lemon balm tea $(5$ $\mathrm{g} / \mathrm{L}$ ), neutralized kombucha beverages (prepared by neutralizing lemon balm-based kombucha beverages with 0.1 $\mathrm{mol} / \mathrm{L}$ of $\mathrm{NaOH}$ ) and heat-denaturated kombucha beverages (both beverages treated at $100{ }^{\circ} \mathrm{C}$ for $5 \mathrm{~min}$ ).

\section{Test bacterial strains}

Test microorganisms were wild strains of bacteria isolated from foodstuffs and water, identified by Vitek ${ }^{\circledR}$ Compact System (bioMérieux, Marcy-l'Etoile, France): Pseudomonas aeruginosa, Proteus sp., Escherichia coli, Citrobacter freundii, Enterobacter cloacae, Salmonella sp. (Gram-negative bacteria), Staphylococcus saprophyticus, Staphylococcus equorum, Bacillus sp., Listeria monocytogenes and Listeria innocua (Gram-positive bacteria).

\section{Antibacterial test}

Antibacterial activity was determined by the agar well diffusion method (30). The strains were grown on Mueller-Hinton slants for $24 \mathrm{~h}$ at $37^{\circ} \mathrm{C}$ and checked for purity. After incubation, the cells were washed from the surface of the agar and suspended in sterile physiological solution. The number of cells in $1 \mathrm{~mL}$ of the suspension used for inoculation, estimated by McFarland nephelometer, was $10^{7} \mathrm{CFU} / \mathrm{mL}$. A volume of $2 \mathrm{~mL}$ of the suspension was 
homogenized with $18 \mathrm{~mL}$ of melted $\left(45^{\circ} \mathrm{C}\right)$ Mueller-Hinton agar and poured into Petri dishes. Wells of $9 \mathrm{~mm}$ in diameter were made in the agar plates with a sterile metal tube by means of a vacuum pump. Samples $(100 \mu \mathrm{L})$ were then transferred into the wells inoculated with test microorganisms. Plates were incubated at $37^{\circ} \mathrm{C}$ for $24 \mathrm{~h}$ and the diameter of the halo zone in each plate (in $\mathrm{mm}$ ) was measured.

\section{Statistical analysis}

Two independent series of kombucha fermentation were performed under the same conditions, each measurement was repeated three times and the results were expressed as mean values \pm standard deviations (S.D.). Statistical analysis was done using Origin v. 7.0 SRO software package (OriginLab Corporation, Northampton, MA, USA) and Microsoft Office Excel 2003 software (Microsoft Corporation, Redmond, WA, USA). The significance of differences was calculated by one-way ANOVA test and then by least significant difference (LSD) test $(p<0.05)$, unless noted otherwise.

\section{Results}

\section{$p H$ values and titratable acidity}

The changes in the basic chemical parameters of lemon balm and traditional kombucha during fermentation are presented in Fig. 1.

The $\mathrm{pH}$ values of the sweetened lemon balm infusion and black tea were 7.05 and 6.94 respectively, which dropped after inoculation to 4.70 and 4.60 . In the first two days of cultivation, the $\mathrm{pH}$ decreased rapidly by about one unit, and after that the total decrease to the end of the process was only 0.6 units. On the other hand, the TA increased during all cultivation period, and an optimum of 4-4.5 g/L was obtained between the third and fourth day of cultivation for both beverages. At the end of the process, lemon balm kombucha contained $8.12 \mathrm{~g} / \mathrm{L}$ of acids, which is by only $0.2 \mathrm{~g} / \mathrm{L}$ higher than in traditional beverage.

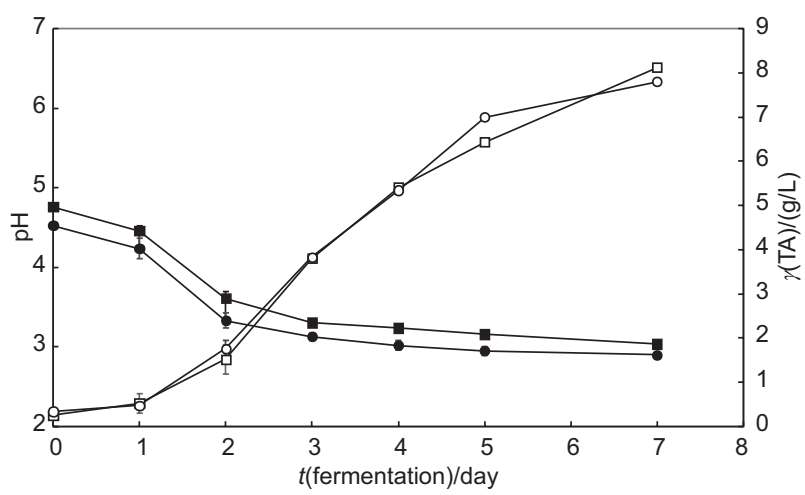

Fig. 1. Changes in the $\mathrm{pH}(\boldsymbol{\bullet}, \bullet)$ values and titratable acidity (TA) $(\square, \circ)$ during fermentation in lemon balm and traditional kombucha, respectively

\section{Total phenols and phenolic compounds}

During fermentation, samples were taken for the determination of total phenols and phenolic compounds (Tables 1 and 2).

After the inoculation with fermentation broth from the previous process, the total phenolic content in both sweetened lemon balm and black tea media increased by approx. $40-120 \mu \mathrm{g} / \mathrm{mL}$. Further changes in the total phenols with fermentation time were progressive. Namely, in the case of the lemon balm fermentation broth, a significant increase in total phenolic compounds was observed in the first $24 \mathrm{~h}$ and then after the fifth day of fermentation, whereas in the traditional procedure, the increasing trend was less significant. The total phenols in lemon balm fermentation broth were higher by about $200 \mu \mathrm{g}$ of GAE per $\mathrm{mL}$ than in the traditional beverage during the whole fermentation process.

The main phenolic compound in lemon balm kombucha is rosmarinic acid, whose content at the end of the fermentation was $18.8 \mu \mathrm{g} / \mathrm{mL}$. The content of rosmarinic acid was approximately the same during the cultivation time. Catechin and gallic acid are the main phenolic compounds in traditional beverage, whose contents on the seventh day of fermentation were 90.7 and $33.3 \mu \mathrm{g} / \mathrm{mL}$, respectively.

Table 1. Contents of total phenols and phenolic compounds in lemon balm kombucha

\begin{tabular}{|c|c|c|c|c|c|c|c|}
\hline \multirow{2}{*}{$\frac{t(\text { fermentation })}{\text { day }}$} & \multirow{2}{*}{$\begin{array}{c}\begin{array}{c}\gamma(\text { total } \\
\text { phenols })\end{array} \\
\begin{array}{c}\mu \mathrm{g} \text { of } \mathrm{GAE} \\
\text { per } \mathrm{mL}\end{array}\end{array}$} & \multicolumn{6}{|c|}{$\gamma($ phenolic compound $) /(\mu \mathrm{g} / \mathrm{mL})$} \\
\hline & & $\begin{array}{c}\text { Rosmarinic } \\
\text { acid }\end{array}$ & $\begin{array}{c}\text { Caffeic } \\
\text { acid }\end{array}$ & Quercetin & $\begin{array}{l}\text { Chlorogenic } \\
\text { acid }\end{array}$ & $\begin{array}{l}\text { Ferulic } \\
\text { acid }\end{array}$ & $\Sigma$ \\
\hline 0 (sweetened tea) & $660.9 \pm 5.2$ & $14.2 \pm 0.2$ & $0.63 \pm 0.03$ & $1.23 \pm 0.09$ & $0.9 \pm 0.1$ & $0.66 \pm 0.05$ & 17.64 \\
\hline 0 (inoculated medium) & $708.6 \pm 9.2$ & $20.3 \pm 0.6$ & $1.04 \pm 0.08$ & $1.12 \pm 0.08$ & $0.62 \pm 0.06$ & $4.3 \pm 0.2$ & 27.33 \\
\hline 1 & $771.3 \pm 8.34$ & $21.7 \pm 0.4$ & $0.91 \pm 0.07$ & $1.4 \pm 0.1$ & $0.59 \pm 0.02$ & $4.6 \pm 0.2$ & 26.16 \\
\hline 2 & $746.9 \pm 8.6$ & $18.9 \pm 0.8$ & $0.75 \pm 0.05$ & $0.90 \pm 0.08$ & $0.71 \pm 0.01$ & $3.3 \pm 0.2$ & 24.55 \\
\hline 3 & $786.4 \pm 10.5$ & $18.8 \pm 0.6$ & $0.87 \pm 0.09$ & $0.61 \pm 0.06$ & $0.78 \pm 0.05$ & $2.1 \pm 0.2$ & 23.11 \\
\hline 4 & $770.1 \pm 12.0$ & $17.1 \pm 0.4$ & $0.9 \pm 0.1$ & $0.7 \pm 0.1$ & $0.73 \pm 0.02$ & $3.4 \pm 0.1$ & 22.90 \\
\hline 5 & $780.6 \pm 12.9$ & $16.6 \pm 0.4$ & $1.05 \pm 0.1$ & $0.63 \pm 0.05$ & $0.75 \pm 0.04$ & $0.7 \pm 0.1$ & 19.69 \\
\hline 7 & $850.3 \pm 5.2$ & $18.8 \pm 0.5$ & $1.2 \pm 0.2$ & $1.0 \pm 0.1$ & $0.79 \pm 0.03$ & $3.1 \pm 0.2$ & 24.78 \\
\hline
\end{tabular}

Values are expressed as mean \pm standard deviation

$\sum=$ sum of identified phenolic compounds; GAE=gallic acid equivalents 
Table 2. Contents of total phenols and phenolic compounds in black tea kombucha

\begin{tabular}{|c|c|c|c|c|c|c|c|}
\hline \multirow{2}{*}{$\frac{t \text { (fermentation })}{\text { day }}$} & \multirow{2}{*}{$\begin{array}{c}\begin{array}{c}\gamma(\text { total } \\
\text { phenols })\end{array} \\
\mu \text { g of GAE } \\
\text { per mL }\end{array}$} & \multicolumn{5}{|c|}{$\gamma($ phenolic compound $) /(\mu \mathrm{g} / \mathrm{mL})$} & \multirow[b]{2}{*}{$\sum$} \\
\hline & & $\begin{array}{c}\text { Gallic } \\
\text { acid }\end{array}$ & Catechin & Epicatechin & Rutin & $\begin{array}{c}\text { Coumaric } \\
\text { acid }\end{array}$ & \\
\hline 0 (sweetened tea) & $347.1 \pm 3.8$ & $0.0 \pm 0$ & $100.8 \pm 1.3$ & $2.66 \pm 0.02$ & $3.61 \pm 0.08$ & $0.80 \pm 0.01$ & 107.91 \\
\hline 0 (inoculated medium) & $468.6 \pm 11.5$ & $36.5 \pm 2.6$ & $101.1 \pm 1.6$ & $0.13 \pm 0.03$ & $4.89 \pm 0.07$ & $0.57 \pm 0.09$ & 143.23 \\
\hline 1 & $530.3 \pm 9.6$ & $35.7 \pm 0.7$ & $110.3 \pm 5.6$ & $0.08 \pm 0.01$ & $7.6 \pm 0.5$ & $0.56 \pm 0.14$ & 154.22 \\
\hline 2 & $545.7 \pm 10.2$ & $28.5 \pm 2.3$ & $101.6 \pm 2.8$ & $0.89 \pm 0.07$ & $7.9 \pm 0.5$ & $0.56 \pm 0.09$ & 139.43 \\
\hline 3 & $557.3 \pm 8.3$ & $24.8 \pm 2.0$ & $95.3 \pm 5.3$ & $0.11 \pm 0.01$ & $5.8 \pm 0.3$ & $0.53 \pm 0.05$ & 126.52 \\
\hline 4 & $532.2 \pm 3.1$ & $29.2 \pm 2.2$ & $90.8 \pm 3.1$ & $0.62 \pm 0.02$ & $7.6 \pm 0.5$ & $0.58 \pm 0.04$ & 128.86 \\
\hline 5 & $538.0 \pm 8.5$ & $29.9 \pm 1.6$ & $86.0 \pm 1.6$ & $0.44 \pm 0.03$ & $2.59 \pm 0.04$ & $0.55 \pm 0.07$ & 119.47 \\
\hline 7 & $574.6 \pm 10.2$ & $33.3 \pm 0.8$ & $90.7 \pm 2.2$ & $0.59 \pm 0.05$ & $7.02 \pm 0.05$ & $0.58 \pm 0.06$ & 132.25 \\
\hline
\end{tabular}

Values are expressed as mean \pm standard deviation

$\sum=$ sum of identified phenolic compounds; GAE=gallic acid equivalents

\section{Antioxidant activity}

Antioxidant activities of lemon balm and traditional kombucha during fermentation are presented in Table 3.

The ${ }^{\circ} \mathrm{OH}$ radical scavenging activity of lemon balm fermentation broth during the whole process was significantly higher $\left(\mathrm{p}<0.05 ; \mathrm{EC}_{50}\right.$ values ranged from 41.0 to 47.5 $\mu \mathrm{L} / \mathrm{mL})$ than that of tea infusion $\left(\mathrm{EC}_{50}=231.9 \mu \mathrm{L} / \mathrm{mL}\right)$. This holds true for traditional beverage since no $\mathrm{EC}_{50}$ value could be found for the black tea infusion in the investigated concentration range of the tested samples $\left(\mathrm{EC}_{50}>\right.$ $300.5 \mu \mathrm{L} / \mathrm{mL}$ ).

Table 3. Antioxidant activities of lemon balm and traditional kombucha

\begin{tabular}{|c|c|c|c|c|}
\hline \multirow{2}{*}{$\frac{t \text { (fermentation) }}{\text { day }}$} & \multicolumn{2}{|c|}{$\mathrm{EC}_{50}(\mathrm{OH}) /(\mu \mathrm{L} / \mathrm{mL})$} & \multicolumn{2}{|c|}{$\mathrm{EC}_{50}(\mathrm{DPPH}) /(\mu \mathrm{L} / \mathrm{mL})$} \\
\hline & $\begin{array}{l}\text { Lemon } \\
\text { balm }\end{array}$ & Traditional & $\begin{array}{l}\text { Lemon } \\
\text { balm }\end{array}$ & Traditional \\
\hline 0 (tea) & $(231.9 \pm 5.5)^{\mathrm{d}}$ & $>300.5$ & $(27.1 \pm 0.9)^{\mathrm{c}}$ & $(72.3 \pm 2.5)^{c}$ \\
\hline 2 & $(41.0 \pm 1.2)^{\mathrm{b}}$ & $(40.4 \pm 2.6)^{\mathrm{d}}$ & $(25.6 \pm 0.7)^{\mathrm{b}, \mathrm{c}}$ & $=(73.6 \pm 3.1)^{c, d}$ \\
\hline 3 & $(35.4 \pm 0.7)^{\mathrm{a}}$ & $(35.5 \pm 0.7)^{\mathrm{c}}$ & $(13.4 \pm 0.3)^{\mathrm{a}}$ & $(76.7 \pm 1.3)^{\mathrm{d}}$ \\
\hline 4 & $(47.7 \pm 0.6)^{c}$ & $(30.1 \pm 2.3)^{\mathrm{b}}$ & $(25.2 \pm 0.4)^{\mathrm{b}}$ & $(60.2 \pm 2.5)^{\mathrm{a}}$ \\
\hline 5 & $(34.2 \pm 0.7)^{a}$ & $(25.4 \pm 2.4)^{\mathrm{a}}$ & $(40.8 \pm 1.1)^{\mathrm{e}}$ & $(65.3 \pm 2.6)^{\mathrm{b}}$ \\
\hline 7 & $(47.5 \pm 0.9)^{\mathrm{c}}$ & $(41.6 \pm 1.1)^{\mathrm{d}}$ & $(30.2 \pm 0.6)^{\mathrm{d}}$ & $(91.2 \pm 4.2)^{\mathrm{e}}$ \\
\hline
\end{tabular}

Values are expressed as mean \pm standard deviation

Different letters in the same column indicate significantly

different values $(\mathrm{p}<0.05)$

The $\mathrm{EC}_{50}$ values of lemon balm samples against DPPH radicals were lower than those of traditional samples, by 25 to $63 \mu \mathrm{L} / \mathrm{mL}$. On the other hand, tea infusions were more efficient against DPPH radicals than both beverages at the end of the process. However, on the fourth day, when an optimum acidity was obtained and the process could be terminated (Fig. 1), both beverages had higher antioxidant activity (and significantly different, $\mathrm{p}<0.05$ ) than tea infusions.

\section{Antibacterial activity}

Antibacterial activity of lemon balm kombucha beverages of different titratable acidity $(4.44$ and $8.12 \mathrm{~g} / \mathrm{L})$ was tested against wild-type bacterial strains isolated from foodstuffs and water (Table 4).

Lemon balm kombucha beverages with different acidities, acetic acid solutions, and heat-denaturated kombucha beverages showed antibacterial activities against all tested strains (Table 4). The clear zones appearing around the wells indicate the bactericidal activity against Gram-negative bacterial strains. Kombucha samples and acetic acid solutions reduced the growth of some Gram-positive bacteria (Staphylococcus equorum, Staphylococcus saprophyticus and Bacillus sp.). Clear inhibition zones of the remaining Gram-positive bacteria that are members of the genus Listeria: Listeria innocua and highly pathogenic Listeria monocytogenes appeared around the wells. Acetic acid solutions and kombucha beverages exhibited almost the same antibacterial activity against the tested strains. Additionally, kombucha beverages with $\mathrm{TA}=8.12 \mathrm{~g} / \mathrm{L}$ produced larger inhibition zones against all tested strains because of the higher concentration of acetic acid. The results given in Table 4 show that the neutralized kombucha beverages expressed inhibitory activity against some Gram-negative bacterial strains: Escherichia coli, Salmonella sp. and Citrobacter freundii (zones of reduced growth were around $25 \mathrm{~mm}$ ).

\section{Discussion}

Changes in chemical parameters ( $\mathrm{pH}$ values and TA) for lemon balm and traditional kombucha were similar during all processes, which indicates that lemon balm provided a sufficient quantity of nitrogen for SCOBY.

The incompatible changes in the $\mathrm{pH}$ and TA could be explained by the buffer capacity of the fermentation broth. Namely, during the fermentation, carbon dioxide is released, and the obtained water solution of $\mathrm{CO}_{2}$ dissociates and produces the amphiprotic hydrocarbonate anion 
Table 4. Antibacterial activity of lemon balm kombucha

\begin{tabular}{|c|c|c|c|c|c|c|c|c|}
\hline \multirow{3}{*}{ Strain } & & \multicolumn{7}{|c|}{$d($ inhibition zone $) / \mathrm{mm}$} \\
\hline & & \multicolumn{2}{|c|}{ Kombucha } & \multicolumn{2}{|c|}{ Acetic acid } & \multicolumn{2}{|c|}{$\begin{array}{l}\text { Heat-denaturated } \\
\text { kombucha }\end{array}$} & \multirow{2}{*}{$\begin{array}{c}\begin{array}{c}\text { Neutralized } \\
\text { kombucha }\end{array} \\
\text { B }\end{array}$} \\
\hline & & $\mathrm{A}$ & B & A & $\mathrm{B}$ & A & $\mathrm{B}$ & \\
\hline \multirow{2}{*}{ Escherichia coli } & 1 & $11.3 \pm 0.6$ & $28 \pm 1$ & $11.3 \pm 0.6$ & n.d. & $11.3 \pm 0.6$ & $29 \pm 1$ & $25.7 \pm 0.6$ \\
\hline & 2 & $13.3 \pm 0.6$ & $34 \pm 1$ & $16.3 \pm 0.6$ & n.d. & $14.7 \pm 0.6$ & $33 \pm 1$ & $29.3 \pm 0.6$ \\
\hline \multirow{2}{*}{ Salmonella sp. } & 1 & $11.7 \pm 0.6$ & $30 \pm 1$ & $12.3 \pm 0.6$ & n.d. & $11.7 \pm 0.6$ & $29.3 \pm 1.2$ & $24.3 \pm 0.6$ \\
\hline & 2 & $15 \pm 0$ & $29.3 \pm 1.2$ & $17.7 \pm 0.6$ & n.d. & $15.7 \pm 0.6$ & $31.7 \pm 0.6$ & $26.3 \pm 0.6$ \\
\hline \multirow{2}{*}{ Enterobacter cloacae } & 1 & $16 \pm 0$ & n.d. & $12 \pm 0$ & n.d. & $15.3 \pm 0.6$ & n.d. & n.d. \\
\hline & 2 & $18.7 \pm 0.6$ & n.d. & $17.7 \pm 0.6$ & n.d. & $18.3 \pm 0.6$ & n.d. & n.d. \\
\hline \multirow{2}{*}{ Citrobacter freundii } & 1 & $13.7 \pm 0.6$ & $26.3 \pm 1.2$ & $12.3 \pm 0.6$ & n.d. & $13.7 \pm 0.6$ & $26 \pm 0$ & $23 \pm 0$ \\
\hline & 2 & $17 \pm 0$ & $23.7 \pm 0.6$ & $18 \pm 0$ & n.d. & $16 \pm 0$ & $25 \pm 0$ & $23 \pm 0$ \\
\hline \multirow{2}{*}{ Proteus sp. } & 1 & $12.3 \pm 0.6$ & n.d. & $10.3 \pm 0.6$ & n.d. & $12 \pm 0$ & n.d. & n.d. \\
\hline & 2 & $18.7 \pm 0.6$ & n.d. & $18.7 \pm 0.6$ & n.d. & $17.7 \pm 0.6$ & n.d. & n.d. \\
\hline \multirow{2}{*}{ Pseudomonas aeruginosa } & 1 & $11.7 \pm 0.6$ & n.d. & $11.3 \pm 0.6$ & n.d. & $11.3 \pm 0.6$ & n.d. & n.d. \\
\hline & 2 & $15.3 \pm 0.6$ & n.d. & $16.7 \pm 0.6$ & n.d. & $15.7 \pm 0.6$ & n.d. & n.d. \\
\hline \multirow{2}{*}{ Listeria monocytogenes } & 1 & $11 \pm 0$ & n.d. & $11 \pm 0$ & n.d. & $10 \pm 0$ & n.d. & n.d. \\
\hline & 2 & $17 \pm 0$ & n.d. & $17 \pm 0$ & n.d. & $14.3 \pm 0.6$ & n.d. & n.d. \\
\hline \multirow{2}{*}{ Listeria innocua } & 1 & $11 \pm 0$ & n.d. & $10.7 \pm 0.6$ & n.d. & $11.3 \pm 1.2$ & n.d. & n.d. \\
\hline & 2 & $17.7 \pm 0.6$ & n.d. & $16.3 \pm 0.6$ & n.d. & $17.3 \pm 0.6$ & n.d. & n.d. \\
\hline \multirow{2}{*}{ Staphylococcus equorum } & 1 & n.d. & $11 \pm 0$ & n.d. & $11 \pm 0$ & n.d. & $10.3 \pm 0.6$ & n.d. \\
\hline & 2 & n.d. & $15.3 \pm 0.6$ & n.d. & $15.3 \pm 0.6$ & n.d. & $14.7 \pm 0.6$ & n.d. \\
\hline \multirow{2}{*}{ Staphylococcus saprophyticus } & 1 & n.d. & $11.7 \pm 0.6$ & n.d. & $10.3 \pm 0.6$ & n.d. & $11.7 \pm 0.6$ & n.d. \\
\hline & 2 & n.d. & $17.7 \pm 0.6$ & n.d. & $17 \pm 0$ & n.d. & $16.7 \pm 0.6$ & n.d. \\
\hline \multirow{2}{*}{ Bacillus sp. } & 1 & n.d. & $11.7 \pm 0.6$ & n.d. & $11.4 \pm 0.6$ & n.d. & $11.7 \pm 0.6$ & n.d. \\
\hline & 2 & n.d. & $15.3 \pm 0.6$ & n.d. & $15 \pm 1$ & n.d. & $14.7 \pm 0.6$ & n.d. \\
\hline
\end{tabular}

Values are expressed as mean \pm standard deviations; $\mathrm{A}=$ clear zone, $\mathrm{B}=$ zone of reduced growth; $1=\mathrm{kombucha}$ and control samples with optimum titratable acidity of $4.4 \mathrm{~g} / \mathrm{L}, 2=$ kombucha and control samples with titratable acidity of $8.12 \mathrm{~g} / \mathrm{L} ;$ n.d.=not detected

$\left(\mathrm{HCO}_{3}^{-}\right)$. This anion easily reacts with hydrogen ions from the organic acids present in the fermentation broth, preventing further changes in the $\mathrm{pH}$, thus contributing to the buffer character of the system (31). This trend towards changes of $\mathrm{pH}$ and titratable acidity is typical for kombucha fermentation and it was also observed by some other authors who used similar cultivation conditions $(1,2,32)$. Although an increase in the TA was observed during the whole fermentation process, some authors reported limited increase in the acetic acid concentration during a prolonged cultivation (60 days) (33). This can be explained by the fact that the high medium acidity and lower amounts of sugar inhibit the fermentation activity of yeasts and production of ethanol (and indirectly, of acetic acid too). In view of the above, TA was used as a critical parameter which determines the end of kombucha fermentation instead of the $\mathrm{pH}$. To obtain a pleasantly sour beverage, the fermentation should be terminated when the TA reaches the optimum value of $4-4.5 \mathrm{~g} / \mathrm{L}$, as confirmed by long-time consumers of kombucha beverage (14).

The time required to obtain kombucha beverages with optimum titratable acidity was less than four days (Fig. 1). This observation is not completely in agreement with the findings of other studies. Some authors obtained the traditional beverage with optimum acidity after four days (31,32), others after six (1) or even eight days (2) of fermentation. The differences in the basic chemical parameters and process duration in different studies may be expected because kombucha cultures originating from different geographic locations have no standardized microbiological and chemical compositions (8).

Nonuniform changes in the phenol concentration during fermentation obtained in our study (Tables 1 and 2) can be explained by biotransformation of phenolic compounds, such as catechins (as well as other complex polyphenols) by the enzymes extracted from SCOBY (11). Additionally, catechins are released from acid-sensitive cells during kombucha fermentation on black and green tea, which could be the reason for the increase in tea polyphenolic content during fermentation. On the other hand, catechins may polymerize to molecules of higher molecular mass, and thus lower the content of polyphenols (34).

The content of rosmarinic acid, which is dominant phenolic compound in lemon balm kombucha was similar (Table 1), which indicates that there is no degradation of this phenolic acid during cultivation. Rosmarinic acid is also recognized as a dominant acid in Melissa officinalis L. extracts, while the other components are caffeic, gentistic, protocatechuic, $p$-hydroxybenzoic and coumaric acids, etc. $(16,19,35)$. 
In traditional kombucha, the following phenolic compounds were determined: gallic acid, catechin, epicatechun, rutin and coumaric acid (Table 2). Previous study has shown that caffeine was the main compound in black tea infusion, followed by gallic, 5-galloylquinic and 4- $p$-coumaroylquinic acids, some flavonols, etc. (36). Caffeine, epigallocatechin gallate and epigallocatechin are mentioned as the main compounds in black tea methanolic extracts $(37,38)$. Certain differences in tea composition are expected and influenced by a number of factors such as species, season, age of the leaves, climate, and horticultural conditions (38). It has been found that the environment, especially climate, has a significant effect on the biosynthesis of catechins and that the formation of chlorophyll during young leaf development takes part in the regulation of individual proportions of catechins in tea (39). Similarly, caffeine content in black teas is affected by the season, stage of plucking and degree of fermentation during tea manufacturing $(38,40)$.

As it can be seen from Tables 1 and 2, the total phenolic content determined by the Folin-Ciocalteu method is higher than the sums of the individual phenolic compounds determined by HPLC. The differences can be explained by the fact that Folin-Ciocalteu method is not an absolute measurement of the amount of phenolics because some other substances such as organic acids, residual sugars, amino acids, proteins, and other hydrophilic compounds interfere with this assay. Besides, various phenolic compounds have different responses in the Folin-Ciocalteu assay $(27,41)$.

Phenolic compounds are called high-level antioxidants because of their ability to scavenge free-radical and active oxygen species such as singlet oxygen, superoxide free radicals and hydroxyl radicals $(42,43)$. Higher antioxidant potential of kombucha beverages compared with non-fermented infusions can be explained by higher content of phenolic compounds in kombucha beverages obtained by fermentation of sweetened black or lemon balm tea (Tables 1 and 2). It is generally believed that polyphenols including catechins, theaflavins and thearubigins are mainly responsible for antioxidant activity of tea $(44,45)$. It has been proposed that some tea fungus metabolites such as vitamins, organic acids, etc. also contribute to the antioxidant activities of kombucha beverages (34). Additionally, the scavenging ability is determined by the key extracellular enzymes that are involved in the structural modification of the medium components during kombucha fermentation (34).

Antioxidant activity of lemon balm kombucha can be explained by the presence of rosmarinic acid (Table 1), which has strong capacity for scavenging free radicals (46). Rosmarinic acid showed an antioxidant activity three times higher than that of Trolox. Rosmarinic acid inhibits xanthine oxidase, and scavenges the surplus free radicals in the body. In addition, rosmarinic acid can reduce $\mathrm{Mo}(\mathrm{VI})$ to $\mathrm{Mo}(\mathrm{V})$, preventing the production of free radicals caused by the metal (46). The activity of rosmarinic acid is due to the structure of its molecule, which contains two phenolic rings, both of which have hydroxyl groups at the ortho-positions. Also, there is a carbonyl group, an unsaturated double bond and a carboxylic acid between the two phenolic rings (46). However, the number of phenolic $\mathrm{OH}$ groups is not always the only factor determining the antioxidant activity. The position of phenolic $\mathrm{OH}$ groups, the presence of other functional groups in the molecule, such as double bonds and their conjugation to $\mathrm{OH}$ and ketonic groups, as well as the polarity and hydrophobicity of the antioxidants also play important roles in the antioxidant activities (47).

Among other phenolic acids (chlorogenic, protocatechuic, caffeic, $p$-coumaric, ferulic, sinapic or umbellic acid), rosmarinic acid exhibited the highest $\mathrm{O}_{2}{ }^{--}$scavenging (48). Also, rosmarinic acid is better antioxidant than synthetic antioxidant butylated hydroxytoluene (BHT) because it reacts more rapidly with DPPH radicals and reaches steady state four times faster (49).

Besides rosmarinic acid, quercetin, which is present in lemon balm fermentation broth (Table 1), also has antioxidant potential because it inhibits the autooxidation of linoleic acid more efficiently than catechin, and exhibits higher ability to scavenge ABTS ${ }^{*+}$ and DPPH radicals than catechin $(42,50,51)$. The antioxidant activity of the flavonol aglycones is also related to the number of hydroxyl groups (43), and besides the ortho-dihydroxy structure that is present in flavonoids in the B ring, some other conditions such as the presence of 2,3-double bond and 4-oxo group in conjugation to $3-\mathrm{OH}$ group $(52,53)$, the absence of catechin and the presence of quercetin are required for a high antioxidant activity. Also, rosmarinic acid had a higher antioxidant activity than catechin and synthetic antioxidants (BHT and butylated hydroxyanisole (BHA)) determined by TEAC (ability to scavenge $\mathrm{ABTS}^{++}$radicals), FRAP assay (the ferric reducing antioxidant power) and higher $\mathrm{HOCl}$ scavenging power (43).

Additionally, it is known that the total antioxidant potential of fruits, vegetables and tea and herbal infusions is more important than the level of any individual specific antioxidant constituent. Because of that, the antioxidant properties of a single compound within a group can vary remarkably, so that the same levels of phenolics do not necessarily correspond to the same antioxidant responses (54). Similarly, the additive and synergistic effects of phytochemicals in fruits and vegetables are responsible for their antioxidant activity, and the benefits of this diet are attributed to the complex mixture of phytochemicals present in whole foods (53).

Other authors showed that antioxidant activity of black and green tea kombucha samples against DPPH radicals (samples volume $100 \mu \mathrm{L}$ ) on the third day of fermentation was around $50 \%$, and decreased in the next four days of the process (55). At the same time, the hydroxyl radical scavenging activity (sample volume $200 \mu \mathrm{L}$ ) showed a mild increasing trend, in the range 40-50\%, during fermentation. In this study, the $\mathrm{EC}_{50}$ values of lemon balm-based kombucha after three days of fermentation were much lower (13.4 and $35.4 \mu \mathrm{L} / \mathrm{mL}$ for DPPH and 'OH radicals, respectively). The study about antioxidant activity of kombucha beverages made from echinacea herb and root (Echinacea purpurea L.), and winter savory (Satureja montana L.) infusions showed higher activity against $\mathrm{DPPH}$ and ${ }^{\circ} \mathrm{OH}$ radicals compared to the tradi- 
tional beverage (14). This indicates that with the use of medicinal herbs for kombucha production, beverages with higher biological activity are produced.

A previous study (24) reported the antimicrobial activity of lemon balm kombucha with $\mathrm{TA}=4.56 \mathrm{~g} / \mathrm{L}$ against reference strains of bacteria, yeasts and moulds. It is likely that wild bacterial strains tested in this study are less sensitive to antimicrobial agents compared to reference strains. Also, wild bacterial strains that are used as test organisms are potential contaminants from the environment during kombucha production. However, wild-type strains had similar inhibition zones as reference strains tested in the previous study (24).

The results of antibacterial activity of kombucha beverages with different TA and control samples confirm previous suppositions that acetic acid is the dominant active component of kombucha $(2,56,57)$. More acidic beverage had higher inhibition zones (Table 4), which proves that the intensity of the antimicrobial activity of kombucha is directly related to the concentration of acetic acid. Acetic acid, as well as other organic acids, can influence the antimicrobial activity by two primary mechanisms: by cytoplasmic acidification and by accumulation of the dissociated acid anion to toxic levels (58). Studies of the antimicrobial activity of kombucha made from sweetened black tea, green tea, and winter savory tea also indicated that acetic acid is the main antimicrobial agent $(57,59)$. All these results prove that the type of tea that is used as the medium for SCOBY cultivation is not crucial for the antimicrobial activity of kombucha.

Bacteriostatic activity of neutralized kombucha against three Gram-negative strains could be explained by the presence of some other antimicrobial components in kombucha beverage apart from acetic acid, probably tannins originating from tea or some metabolites produced by the SCOBY (2). The antimicrobial activity of heat-denaturated kombucha beverages indicates that the antimicrobial components are thermostable and are not large proteins.

Although there are no published data on the antimicrobial activity of unfermented lemon balm tea (at the drinkable level of tea of $5 \mathrm{~g} / \mathrm{L}$ ), some studies report antimicrobial activity of 20 and $50 \%$ lemon balm essential oil solutions (20), as well as of ethanolic extracts of leaves and twigs (60). Rosmarinic acid was recognized as the main bioactive compound present in Melissa officinalis L. extracts, which inhibits the growth of bacteria, yeasts and moulds, when present in a concentration range of 0.12 to $16 \mathrm{mg} / \mathrm{mL}(61)$.

The slight inhibitory activity of unfermented lemon balm infusion in the present study was obtained only against Gram-positive bacteria Enterobacter cloacae (inhibition zone of reduced growth of $(11.3 \pm 0.3) \mathrm{mm}$ ) and Gram-negative bacteria Proteus sp. (clear zone of $(15.7 \pm 0.9) \mathrm{mm})$. This activity can be explained by the presence of rosmarinic acid as the main phenolic component (Table 1). Soluble phenolics are thought to exert their antimicrobial effect by causing hyperacidification at the plasma membrane interface of the microorganism, which potentially results in disruption of the $\mathrm{H}^{+}$-ATPase required for ATP synthesis (62). Unfermented black and green tea at $70 \mathrm{~g}$ of dry tea leaves per litre of boiled water showed the absence of antimicrobial properties against most of the tested organisms (63). Black and green tea infusions at concentration of $10 \mathrm{~g} / \mathrm{L}$ possess antibacterial activity against Streptococcus sobrinus, Streptococcus mutans (64), Staphylococcus aureus, Escherichia coli, Pseudomonas aeruginosa (65) and at concentration of $15 \mathrm{~g} / \mathrm{L}$ against Bacillus cereus, Microccocus luteus and Pseudomonas aeruginosa (66), which are higher than those used in our study. However, the levels of tea above $4.4 \mathrm{~g} / \mathrm{L}$ had an offensive bitter taste and were undrinkable (63). The absence of or an insignificant antimicrobial activity of black and green teas at drinkable levels could be explained by the low concentrations of tea and its active components (polyphenols/tannins) $(56,59)$. Also, unfermented winter savory (Satureja montana L.) tea at $5 \mathrm{~g} / \mathrm{L} \mathrm{did}$ not show antimicrobial activity against the tested microorganisms (57).

\section{Conclusion}

Sweetened lemon balm (Melissa officinalis L.) infusion can be successfully used as the medium for kombucha fermentation, yielding a beverage of significant antioxidant and antimicrobial properties. Lemon balm-based kombucha showed a higher antioxidant activity against DPPH radicals compared to the traditional beverage (made from black tea). Also, the antioxidant activity of lemon balm-based kombucha with optimum acidity $(\mathrm{TA}=4.4 \mathrm{~g} / \mathrm{L})$ was higher than that of lemon balm infusion. Active components responsible for the antioxidant activity are probably rosmarinic acid, other phenolic compounds, and SCOBY metabolites. Lemon balm kombucha exhibited antibacterial activity against all tested wild-type strains, including pathogenic Gram-positive and Gram-negative bacteria. The main antibacterial component is acetic acid, whose concentration in kombucha beverage influences directly its antimicrobial potential. However, the antibacterial activity of neutralized kombucha against several bacterial strains indicates that the presence of some non-acidic components may contribute to this bioacivity.

\section{Acknowledgements}

This research was financially supported by the Ministry of Education and Science of Republic of Serbia (project no. 31044).

\section{References}

1. P.J. Blanc, Characterization of tea fungus metabolites, Biotechnol. Lett. 18 (1996) 139-142. http://dx.doi.org/10.1007/BF00128667

2. G. Sreeramulu, Y. Zhu, W. Knol, Kombucha fermentation and its antimicrobial activity, J. Agric. Food Chem. 48 (2000) 2589-2594. http://dx.doi.org/10.1021/jf991333m

3. C.J. Greenwalt, K.H. Steinkraus, R.A. Ledford, Kombucha, the fermented tea: Microbiology, composition, and claimed health effects, J. Food Protect. 63 (2000) 976-981.

4. I. Janković, M. Stojanović, Microbial and chemical composition, growth, therapeutical and antimicrobial characteristics of tea fungus, Mikrobiologija, 33 (1994) 25-34. 
5. C.H. Liu, W.H. Hsu, F.L. Lee, C.C. Liao, The isolation and identification of microbes from a fermented tea beverage Haipao, and their interaction during Haipao fermentation, Food Microbiol. 13 (1996) 407-415. http://dx.doi.org/10.1006/fmic.1996.0047

6. M. Sievers, C. Lanini, A. Weber, U. Schuler-Schmid, M. Teuber, Microbiology and fermentation balance in kombucha beverage obtained from a tea fungus fermentation, Syst. Appl. Microbiol. 18 (1995) 590-594.

http://dx.doi.org/10.1016/S0723-2020(11)80420-0

7. B. Bauer-Petrovska, L. Petrushevska-Tozi, Mineral and water soluble vitamins content in the kombucha drink, Int. J. Food Sci. Tech. 35 (2000) 201-205. http://dx.doi.org/10.1046/j.1365-2621.2000.00342.x

8. A.L. Teoh, G. Heard, J. Cox, Yeast ecology of kombucha fermentation, Int. J. Food Microbiol. 95 (2004) 119-126. http://dx.doi.org/10.1016/j.ijfoodmicro.2003.12.020

9. C. Pasha, G. Reddy, Nutritional and medicinal improvement of black tea by yeast fermentation, Food Chem. 89 (2005) 449-453. http://dx.doi.org/10.1016/j.foodchem.2004.02.054

10. C. Dufresne, E. Farnworth, Tea, kombucha and health: A review, Food Res. Int. 33 (2000) 409-421. http://dx.doi.org/10.1016/S0963-9969(00)00067-3

11. R. Jayabalan, S. Marimuthu, K. Swaminathan, Changes in content of organic acids and tea polyphenols during kombucha tea fermentation, Food Chem. 102 (2007) 392-398. http://dx.doi.org/10.1016/j.foodchem.2006.05.032

12. N. Hoffmann: Basic Building Blocks, Nutrients and Growth Factors: What the Kombucha Culture Needs to Survive (1998) (http://www.kombu.de/nutrient.htm).

13. H. Battikh, A. Bakhrouf, E. Ammar, Antimicrobial effect of Kombucha analogues, LWT-Food Sci. Technol. 47 (2012) 71-77.

http://dx.doi.org/10.1016/j.lwt.2011.12.033

14. D. Cvetković, Kombucha made from medical herbs - Biological activity and fermentation, $\mathrm{PhD}$ Thesis, University of Novi Sad, Novi Sad, Serbia (2008) (in Serbian).

15. A. Velićanski, Characterization of functional lemon balm (Melissa officinalis L.) beverage obtained by physiological activity of tea fungus, PhD Thesis, University of Novi Sad, Novi Sad, Serbia (2012) (in Serbian).

16. A.P. Carnat, A. Carnat, D. Fraisse, J.L. Lamaison, The aromatic and polyphenolic composition of lemon balm (Melissa officinalis L. subsp. officinalis) tea, Pharm. Acta Helv. 72 (1998) 301-305. http://dx.doi.org/10.1016/S0031-6865(97)00026-5

17. S. Stangler Herodež, M. Hadolin, M. Škerget, Ž. Knez, Solvent extraction study of antioxidants from Balm (Melissa officinalis L.) leaves, Food Chem. 80 (2003) 257-282.

18. R. Bahtıyarca Bağdat, B. Coşge, The essential oil of lemon balm (Melissa officinalis L.), its components and using fields, J. Fac. Agric. OMU, 21 (2006) 116-121.

19. K. Dastmalchi, H.J.D. Dorman, P.P. Oinonen, Y. Darwis, I. Laakso, R. Hiltunen, Chemical composition and in vitro antioxidative activity of a lemon balm (Melissa officinalis L.) extract, LWT-Food Sci. Technol. 41 (2008) 391-400. http://dx.doi.org/10.1016/j.lwt.2007.03.007

20. N. Mimica Dukić, B. Božin, M. Soković, N. Simin, Antimicrobial and antioxidant activities of Melissa officinalis L. (Lamiaceae) essential oil, J. Agric. Food Chem. 52 (2004) 2485-2489. http://dx.doi.org/10.1021/jf030698a

21. E. Capecka, A. Mareczek, M. Leja, Antioxidant activity of fresh and dry herbs of some Lamiaceae species, Food Chem. 93 (2005) 223-226.

http://dx.doi.org/10.1016/j.foodchem.2004.09.020
22. J. Bouayed, K. Piri, H. Rammal, A. Dicko, F. Desor, C. Younos et al., Comparative evaluation of the antioxidant potential of some Iranian medicinal plants, Food Chem. 104 (2007) 364-368. http://dx.doi.org/10.1016/j.foodchem.2006.11.069

23. A.S. Velićanski, D.D. Cvetković, S.L. Markov, V.T. Tumbas, S.M. Savatović, Antimicrobial and antioxidant activity of lemon balm kombucha, Acta Period. Technol. 38 (2007) 165172. http://dx.doi.org/10.2298/APT0738165V

24. D.D. Četojević-Simin, A.S. Velićanski, D.D. Cvetković, S.L. Markov, J.Ž. Mrđanović, V.V. Bogdanović et al., Bioactivity of lemon balm kombucha, Food Bioprocess Technol. 5 (2012) 1756-1765. http://dx.doi.org/10.1007/s11947-010-0458-6

25. S.L. Markov, R.V. Malbaša, M.J. Hauk, D.D. Cvetković, Investigation of tea fungus microbe associations. I. The yeasts, Acta Period. Technol. 32 (2001) 133-138.

26. J.L. Jacobson: Introduction to Wine Laboratory Practices and Procedures, Springer Science+Business Media, Inc., New York, NY, USA (2006) pp. 275-277.

27. V.L. Singleton, R. Orthfer, R.M. Lamuela-Raventos, Analysis of total phenols and other oxidation substrates and oxidant by means of Folin-Ciocalteu reagent, Methods Enzymol. 299 (1999) 152-178. http://dx.doi.org/10.1016/S0076-6879(99)99017-1

28. J.M. Čanadanović-Brunet, G.S. Ćetković, S.M. Djilas, V.T. Tumbas, S.S. Savatović, A.I. Mandić et al., Radical scavenging and antimicrobial activity of horsetail (Equisetum arvense L.) extracts, Int. J. Food Sci. Technol. 44 (2009) 269-278. http://dx.doi.org/10.1111/j.1365-2621.2007.01680.x

29. M.E. Cuvelier, H. Richard, C. Berset, Comparison of the antioxidative activity of some acid-phenols: Structure-activity relationships, Biosci. Biotech. Biochem. 56 (1992) 324-325. http://dx.doi.org/10.1271/bbb.56.324

30. W.J. Mayo: Chemical Methods of Control: Antimicrobial Drugs. In: Laboratory Experiments in Microbiology, T.R. Johnson, C.L. Case (Eds.), The Benjamin/Cummings Publishing Company, San Francisco, CA, USA (1998) pp. 179-181.

31. D. Cvetković, S. Markov, M. Djurić, D. Savić, A. Velićanski, Specific interfacial area as a key variable in scaling-up Kombucha fermentation, J. Food Eng. 85 (2008) 387-392. http://dx.doi.org/10.1016/j.jfoodeng.2007.07.021

32. G. Belloso-Morales, H. Hernández-Sánchez, Manufacture of a beverage from cheese whey using a 'tea fungus' fermentation, Rev. Latinoam. Microbiol. 45 (2003) 5-11.

33. C. Chen, B.Y. Liu, Changes in major components of tea fungus metabolites during prolonged fermentation, J. Appl. Microbiol. 89 (2000) 834-839. http://dx.doi.org/10.1046/j.1365-2672.2000.01188.x

34. S.C. Chu, C. Chen, Effects of origins and fermentation time on the antioxidant activities of kombucha, Food Chem. 98 (2006) 502-507. http://dx.doi.org/10.1016/j.foodchem.2005.05.080

35. G. Zgórka, K. Glowniak, Variation of free phenolic acids in medicinal plants belonging to the Lamiaceae family, J. Pharmaceut. Biomed. 26 (2001) 79-87. http://dx.doi.org/10.1016/S0731-7085(01)00354-5

36. D. Del Rio, A.J. Stewart, W. Mullen, J. Burns, M.E.J. Lean, F. Brighenti et al., HPLC-MS analyses of phenolic compounds and purine alkaloids in green and black tea, J. Agric. Food Chem. 52 (2004) 2807-2815. http://dx.doi.org/10.1021/jf0354848

37. Y. Zuo, H. Chen, Y. Deng, Simultaneous determination of catechins, caffeine and gallic acids in green, Oolong, black and pu-erh teas using HPLC with a photodiode array detector, Talanta, 57 (2002) 307-316. http://dx.doi.org/10.1016/S0039-9140(02)00030-9 
38. C. Cabrera, R. Giménez, M.C. López, Determination of tea components with antioxidant activity, J. Agric. Food Chem. 51 (2003) 4427-4435. http://dx.doi.org/10.1021/jf0300801

39. K. Wei, L. Wang, J. Zhou, W. He, J. Zeng, Y. Jiang et al., Catechin contents in tea (Camellia sinensis) as affected by cultivar and environment and their relation to chlorophyll contents, Food Chem. 125 (2011) 44-48.

http://dx.doi.org/10.1016/j.foodchem.2010.08.029

40. L. Yao, X. Liu, Y. Jiang, N. Caffin, B. D'Arcy, R. Singanusong et al., Compositional analysis of teas from Australian supermarkets, Food Chem. 94 (2006) 115-122. http://dx.doi.org/10.1016/j.foodchem.2004.11.009

41. A. Rigo, F. Vianello, G. Clementi, M. Rossetto, M. Scarpa, U. Vrhovšek et al., Contribution of proanthocyanidins to the peroxy radical scavenging capacity of some Italian red wines, J. Agric. Food Chem. 48 (2000) 1996-2002. http://dx.doi.org/10.1021/jf991203d

42. C.A. Rice-Evans, N.J. Miller, G. Paganga, Antioxidant properties of phenolic compounds, Trends Plant Sci. 2 (1997) 152159. http://dx.doi.org/10.1016/S1360-1385(97)01018-2

43. M.A. Soobrattee, V.S. Neergheen, A. Luximon-Ramma, O.I. Aruoma, T. Bahorum, Phenolics as potential antioxidant therapeutic agents: Mechanism and action, Mutation Research, 579 (2006) 200-213. http://dx.doi.org/10.1016/j.mrfmmm.2005.03.023

44. W. Łuczaj, E. Skrzydlewska, Antioxidative properties of black tea, Prev. Med. 40 (2005) 910-918. http://dx.doi.org/10.1016/j.ypmed.2004.10.014

45. A.E. Sharangi, Medicinal and therapeutic potentialities of tea (Camellia sinensis L.) - A review, Food Res. Int. 42 (2009) 529-535.

http://dx.doi.org/10.1016/j.foodres.2009.01.007

46. B. Tepe, O. Eminagaoglu, H. Askin Akpulat, E. Ayidin, Antioxidant potentiala and rosmarinic acid levels of the methanolic extracts of Salvia verticillata (L.) subsp. verticillata and S. verticillata (L.) subsp. amasiaca (Freyn \& Bornm.) Bornm., Food Chem. 100 (2007) 985-989. http://dx.doi.org/10.1016/j.foodchem.2005.10.062

47. N. Erkan, G. Ayranci, E. Ayranci, Antioxidant activities of rosemory (Rosmarinus officinalis L.) extract, blackseed (Nigella sativa L.) essential oil, carnosic acid, rosmarinic acis and sesamol, Food Chem. 110 (2008) 76-82. http://dx.doi.org/10.1016/j.foodchem.2008.01.058

48. P. Terpinc, H. Abramovič, A kinetic approach for evaluation of the antioxidant activity of selected phenolic acids, Food Chem. 121 (2010) 366-371. http://dx.doi.org/10.1016/j.foodchem.2009.12.037

49. C.S. Romano, K. Abadi, V. Repetto, A.A. Vojnov, S. Moreno, Synergistic antioxidant and antibacterial activity of rosemary plus butylated derivatives, Food Chem. 115 (2009) 456-461. http://dx.doi.org/10.1016/j.foodchem.2008.12.029

50. J. Torel, J. Cillard, P. Cillard, Antioxidant activity of flavonoids and reactivity with peroxy radical, Phytochemistry, 25 (1986) 383-385. http://dx.doi.org/10.1016/S0031-9422(00)85485-0

51. A. Seyoum, K. Asres, F. Kandeel El-Fiky, Structure radical scavenging activity relationships of flavonoids, Phytochemistry, 67 (2006) 2058-2070. http://dx.doi.org/10.1016/j.phytochem.2006.07.002

52. W. Bors, W. Heller, C. Michel, M. Saran, Flavonoids as antioxidants: Determination of radical-scavenging efficiencies,
Methods Enzymol. 186 (1990) 343-355.

http://dx.doi.org/10.1016/0076-6879(90)86128-I

53. V.T. Tumbas, J.M. Čanadanović-Brunet, D.D. Četojević-Simin, G.S. Ćetković, S.M. Đilas, L. Gille, Effect of rosehip (Rosa canina L.) phytochemicals on stable free radicals and human cancer cells, J. Sci. Food Agr. 92 (2012) 1273-1281. http://dx.doi.org/10.1002/jsfa.4695

54. A.K. Atoui, A. Mansouri, G. Boskou, P. Kefalas, Tea and herbal infusions: Their antioxidant activity and phenolic profile, Food Chem. 89 (2005) 27-36. http://dx.doi.org/10.1016/j.foodchem.2004.01.075

55. R.V. Malbaša, E.S. Lončar, J.S. Vitas, J.M. ČanadanovićBrunet, Influence of starter cultures on the antioxidant activity of kombucha beverage, Food Chem. 127 (2010) 17271731. http://dx.doi.org/10.1016/j.foodchem.2011.02.048

56. K.H. Steinkraus, K.B. Shapiro, J.H. Hotchkiss, R.P. Mortlock, Investigations into the antibiotic activity of tea fungus/Kombucha beverage, Acta Biotechnol. 16 (1996) 199-205. http://dx.doi.org/10.1002/abio.370160219

57. D.D. Četojević Simin, G.M. Bogdanović, D.D. Cvetković, A.S. Velićanski, Antiproliferative and antimicrobial activity of traditional Kombucha and Satureja montana L. Kombucha, J. BUON, 13 (2008) 395-401.

58. E. Mani-López, H.S. García, A. López-Malo, Organic acids as antimicrobials to control Salmonella in meat and poultry products, Food Res. Int. 45 (2012) 713-721. http://dx.doi.org/10.1016/j.foodres.2011.04.043

59. G. Sreeramulu, Y. Zhu, W. Knol, Characterization of antimicrobial activity in Kombucha fermentation, Acta Biotechnol. 21 (2001) 49-56.

http://dx.doi.org/10.1002/1521-3846(200102)21:1<49: :AID-ABIO49>3.0.CO;2-G

60. Ö. Ertürk, Antibacterial and antifungal activity of ethanolic extracts from eleven spice plants, Biologia, 61 (2006) 275-278. http://dx.doi.org/10.2478/s11756-006-0050-8

61. T. Mencherini, P. Picerno, C. Scesa, R. Aquino, Triterpene, antioxidant, and antimicrobial compounds from Melissa officinalis, J. Nat. Prod. 70 (2007) 1889-1894. http://dx.doi.org/10.1021/np070351s

62. D.A. Vattem, Y.T. Lin, R.G. Labbe, K. Shetty, Antimicrobial activity against selected food-borne pathogens by phenolic antioxidants enriched cranberry pomace by solid-state bioprocessing using food-grade fungus Rhizopus oligosporus, Process Biochem. 39 (2004) 1939-1946. http://dx.doi.org/10.1016/j.procbio.2003.09.032

63. C.J. Greenwalt, R.A. Ledford, K.H. Steinkraus, Determination and characterization of the anti-microbial activity of the fermented tea Kombucha, LWT-Food Sci. Technol. 31 (1998) 291-296. http://dx.doi.org/10.1006/fstl.1997.0354

64. M. Bancirova, Comparison of the antioxidant capacity and the antimicrobial activity of black and green tea, Food Res. Int. 43 (2010) 1379-1382. http://dx.doi.org/10.1016/j.foodres.2010.04.020

65. M.P. Almajano, R. Carbó, J.A. López Jiménez, M.H. Gordon, Antioxidant and antimicrobial activities of tea infusions, Food Chem. 108 (2008) 55-63. http://dx.doi.org/10.1016/j.foodchem.2007.10.040

66. J. Oh, H. Jo, A. R. Cho, S.J. Kim, J. Han, Antioxidant and antimicrobial activities of various leafy herbal teas, Food Control, 31 (2013) 403-409.

http://dx.doi.org/10.1016/j.foodcont.2012.10.021 